\title{
Human papilloma virus detection by in situ hybridisation signal amplification based on biotinylated tyramine deposition
}

\author{
P J Poddighe, J Bulten, H M J Kerstens, J C M Robben, W J G Melchers, \\ A G J M Hanselaar
}

\begin{abstract}
Aim-To describe a method for amplifying human papilloma virus (HPV) in situ hybridisation (ISH) signals.

Methods-Three human cervical cell lines, namely CaSKi, HeLa and SiHa, containing different copy numbers of integrated HPV DNA were studied. Following ISH, catalysed reporter deposition (CARD), based on the deposition of biotinylated tyramine at the location of the DNA probe, was used to amplify the ISH signal.

Results-Using CARD-ISH, one to three HPV type 16 copies were detected in situ both in cell suspensions and paraffin wax sections of SiHa cells. CARD-ISH can also be used to detect oncogenic HPV DNA sequences, such as HPV types 16 and 18 , in routinely processed formalin fixed, paraffin wax embedded cervical specimens. Conclusions-CARD-ISH is a fast and highly sensitive ISH method for the routine detection of low copy number HPV DNA sequences in cervical cell lines and routinely processed tissue sections. Application of this technology also enables the routine detection and cellular localisation of other viral DNA sequences present at copy numbers below the detection limit of conventional ISH methods.

( Clin Pathol: Mol Pathol 1996;49:M340-M344)
\end{abstract}

Keywords: in situ hybridisation, signal amplification, cell lines, human papilloma virus, cervix uteri.

Department of Pathology, University Hospital Nijmegen, The Netherlands

P J Poddighe $\mathrm{J}$ Bulten

H M J Kerstens

J C M Robben

A G J M Hanselaar

Department of Medical Microbiology W J G Melchers

Correspondence to Dr P J Poddighe, Department of Pathology, University Hospital

Nijmegen, Geert Grooteplein Zuid 24, 6525 GA Nijmegen, The Netherlands.

Accepted for publication 27 August 1996
Recently, we described a novel ISH signal amplification method, using catalysed reporter deposition (CARD-ISH). ${ }^{1}$ This amplification method is based on the deposition of biotinylated tyramine by the activity of horseradish peroxidase (HRP) at the location of the DNA probe. The procedure was introduced initially for immunoassays and immunohistochemistry. $^{2-4}$ In our method, the biotinylated tyramine precipitate can be visualised within cells using fluorochrome or enzyme labelled avidin. The detection limit is increased substantially for both brightfield and fluorescence ISH. The CARD-ISH signal amplification technique is particularly suitable for the visualisation of low copy number DNA sequences, but may also be valuable for the detection of (oncogenic) viruses. The CARD-ISH procedure is rapid, flexible, and easy to implement in standard ISH protocols. ${ }^{15}$
Infection with certain human papilloma virus (HPV) types, especially types 16 and 18 , has been postulated to be a high risk factor for the development of human squamous cell carcinoma of the uterine cervix. ${ }^{6-9}$ Using PCR, viral infection can be detected rapidly even if only a few cells in a given tissue or cytological sample contain the DNA sequence of interest. ${ }^{10}$ However, one of the major disadvantages of PCR analysis is that there is no direct correlation with morphology. ${ }^{11}$ The application of ISH techniques for the detection of HPV sequences is preferred in order to correlate the presence of HPV DNA with morphological aspects of the cells or tissue. However, the value of conventional ISH techniques is limited by its detection sensitivity of about 20 copies per cell. $^{10}$ Nuovo et $a l^{1213}$ have developed a PCR-ISH technique that combines the extreme sensitivity of PCR amplification and morphological preservation of ISH, and have applied this technique to cell lines ${ }^{12}$ and formalin fixed, paraffin wax embedded section ${ }^{13}$ for the detection of HPV DNA. Disadvantages of this procedure are that it can lead to false positive results because of non-specific PCR reactions and that it is laborious and therefore is not always available routinely. In an attempt to overcome these disadvantages, we adapted the CARD-ISH method for use on formalin fixed, paraffin wax embedded cervical sections.

\section{Methods}

CELL AND TISSUE SAMPLES

The human cervical carcinoma cell lines $\mathrm{CaSk}$ (ATCC; CRL1550), containing about 500 integrated copies of HPV 16 DNA, HeLa (ATCC; CCL2), containing about 20-50 integrated copies of HPV $18 \mathrm{DNA}$, and $\mathrm{SiHa}$ (ATCC; HTB35), containing one to three integrated copies of HPV 16 DNA, were used to determine the sensitivity and specificity of the CARD-ISH method. After being cultured, the cells are mixed with human lymphocytes, fixed in $70 \%$ ethanol $\left(-20^{\circ} \mathrm{C}\right)$ and stored at $-30^{\circ} \mathrm{C}$ pending analysis.

For analysis, $5 \mu \mathrm{l}$ of each cell suspension was spotted onto Superfrost Plus glass slides (Merck, Darmstadt, Germany) and dried in air. An appropriate part of each cell suspension, depending on cell density, was, after centrifugation, mixed with agar (volume 1:1), fixed in $4 \%$ buffered formalin and embedded in paraffin wax. 


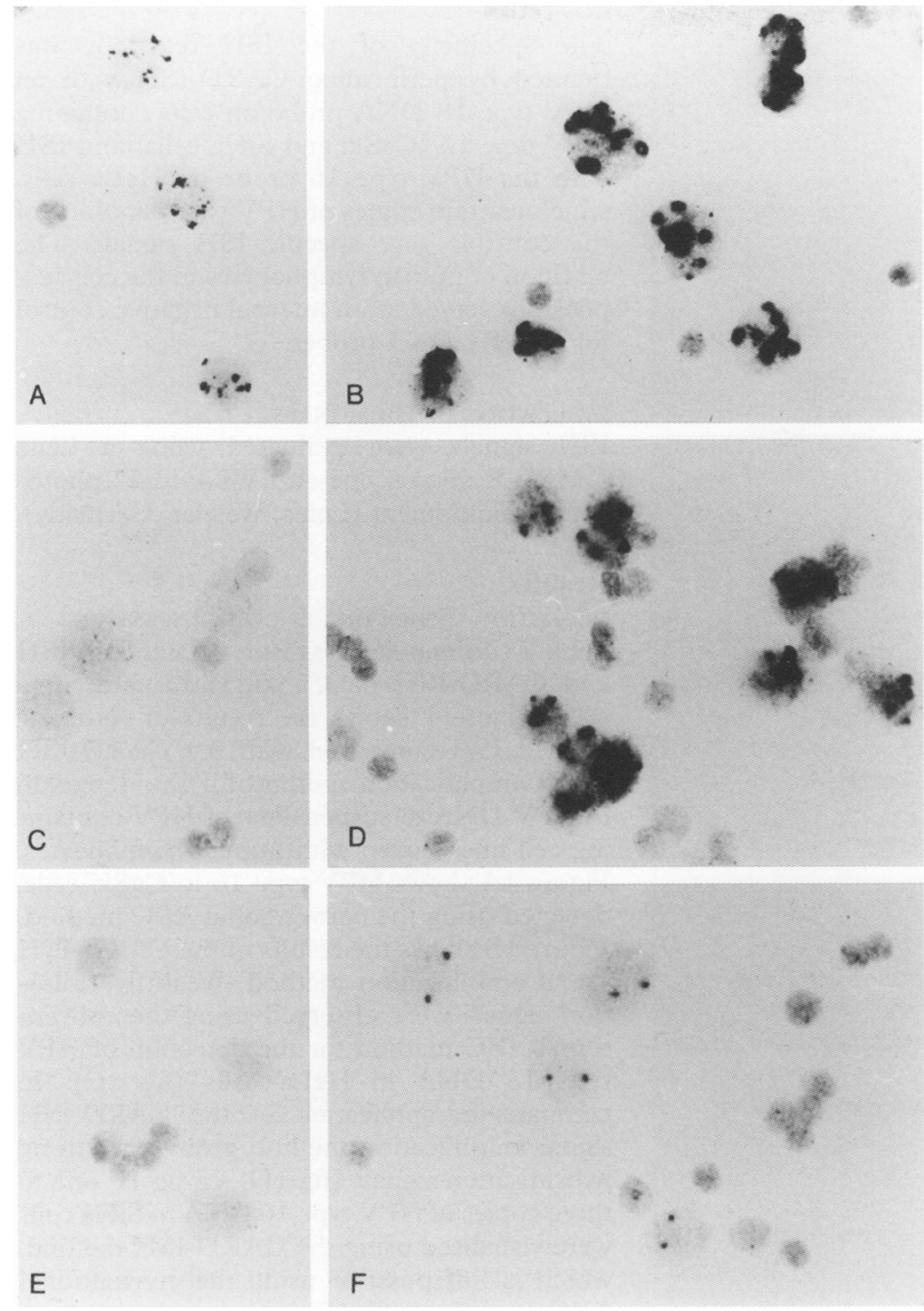

Figure 1 Results of CARD-ISH signal amplification on cervical cancer cell lines. $(A)$ and $(B)$ CaSki cells hybridised with a biotinylated DNA probe specific for HPV type 16. (C) and (D) HeL a cells hybridised with a biotinylated DNA probe specific for HPV type 18. (E) and (F) SiHa cells hybridised with a biotinylated DNA probe specific for HPV type 16. Visualisation was achieved using the standard $A B C$ technique $(A, C, E)$, and by the $C A R D$ method $(B, D, F)$. Human lymphocytes served as an internal negative control. Original magnification $\times 400$.
Table 1 Comparison of the sensitivity and specificity of the standard ISH and CARD-ISH methods in the detection of HPV DNA in human cervical cancer cell lines

\begin{tabular}{llll}
\hline Cell line & HPV type & ISH & CARD-ISH \\
\hline $\begin{array}{llll}\text { In suspension } \\
\text { CaSki }\end{array}$ & 16 & ++ & ++++++ \\
& 18 & - & - \\
HeLa & 16 & - & - \\
& 18 & + & +++ \\
SiHa & 16 & - & ++ \\
& 18 & - & - \\
Human & 16 & - & - \\
lymphocytes & 18 & - & - \\
& & & \\
In paraffin wax & 16 & ++ & +++++ \\
CaSki & 18 & - & - \\
& 16 & - & - \\
HeLa & 18 & + & +++ \\
& 16 & - & ++ \\
SiHa & 18 & - & - \\
Human & 16 & - & - \\
lymphocytes & 18 & - & -
\end{tabular}

Score:,- no signal; + to ++++++ , weak to very strong signal.

probes specific for HPV types 16 and 18 were labelled by nick translation with biotin-14dATP, as described by the manufacturer (BRL, Gaithersburg, Maryland, USA). The hybridisation mixture $(15 \mu \mathrm{l})$ contained $60 \%$ deionised formamide (Merck), $10 \%$ dextran sulphate (Sigma), $2 \times$ SSC $(\mathrm{pH} 7.0 ; 1 \times \mathrm{SSC}=0.15 \mathrm{M}$ sodium chloride, $0.015 \mathrm{M}$ sodium citrate), 50 $\mathrm{ng} / \mu \mathrm{l}$ herring sperm DNA (Boehringer, Mannheim, Germany) and $2 \mathrm{ng} / \mu \mathrm{l}$ probe. The slides were heated for three minutes at $95^{\circ} \mathrm{C}$ (cytospin preparations) or for 10 minutes at $80^{\circ} \mathrm{C}$ (paraffin wax sections) to denature the probe and target DNA. After hybridisation overnight at $37^{\circ} \mathrm{C}$ in a moist chamber, coverslips were removed by immersing the slides in $2 \times \mathrm{SSC}(\mathrm{pH} 7.0)$ at $42^{\circ} \mathrm{C}$. Posthybridisation washes at $42^{\circ} \mathrm{C}$ were carried out twice for five minutes in $60 \%$ formamide $/ 2 \times$ SSC, $\mathrm{pH} 7.0$, and twice for five minutes in $2 \times$ SSC, $\mathrm{pH}$ 7.0. The slides were then rinsed in phosphate buffered saline (PBS) $/ 0.05 \%$ Tween-20.

Hybridised DNA probes were detected immunohistochemically using the HRP labelled avidin-biotin-complex (ABC) method ${ }^{15}$ as described previously. ${ }^{1} \mathrm{HRP}$ was visualised via the diaminobenzidine (DAB; Sigma) $/ \mathrm{H}_{2} \mathrm{O}_{2}$ (Merck) reaction. cinomas) were selected after histological examination of haematoxylin and eosin stained $4 \mu \mathrm{m}$ tissue sections.

Sections, $4 \mu \mathrm{m}$ thick, of the paraffin wax embedded cell suspensions and samples of cervical tissue were mounted on Superfrost Plus glass slides and heated overnight at $60^{\circ} \mathrm{C}$. After dewaxing in xylene and rinsing in methanol, endogenous peroxidase activity was blocked by incubating the slides with $1 \% \mathrm{H}_{2} \mathrm{O}_{2}$ /methanol for 20 minutes at room temperature. The slides were then rinsed in methanol and dried in air.

IN SITU HYBRIDISATION

Ethanol fixed cell samples and paraffin wax sections were pretreated as described previously. ${ }^{14}$ Preteatment included the elimination of basic proteins and digestion by pepsin (Sigma, St Louis, Missouri, USA). DNA
CARD-ISH SIGNAL AMPLIFICATION

Briefly, the slides were pretreated using the ABC method, incorporating mouse anti-biotin $(\mathrm{M} \alpha \mathrm{B})$, biotinylated horse anti-mouse (Hs $\alpha \mathrm{M}$ bio), and ABC. After rinsing the slides in PBS/ Tween and PBS, biotinylated tyramine was covalently bound to electron rich moieties on the surface through the enzymatic reaction of $\mathrm{HRP}$ with $0.01 \% \mathrm{H}_{2} \mathrm{O}_{2}$ in PBS for two minutes at room temperature. ${ }^{2} \mathrm{~A}$ biotinylated tyramine concentration of $0.7 \mu \mathrm{M}$ was used for the cell suspensions and of $0.07 \mu \mathrm{M}$ for the paraffin wax samples. After rinsing in PBS/Tween, samples were incubated in ABComplex for 20 minutes at $37^{\circ} \mathrm{C}$ to detect the new biotin source. Finally, the hybrid was visualised using $\mathrm{DAB} / \mathrm{H}_{2} \mathrm{O}_{2}$ as described earlier. 


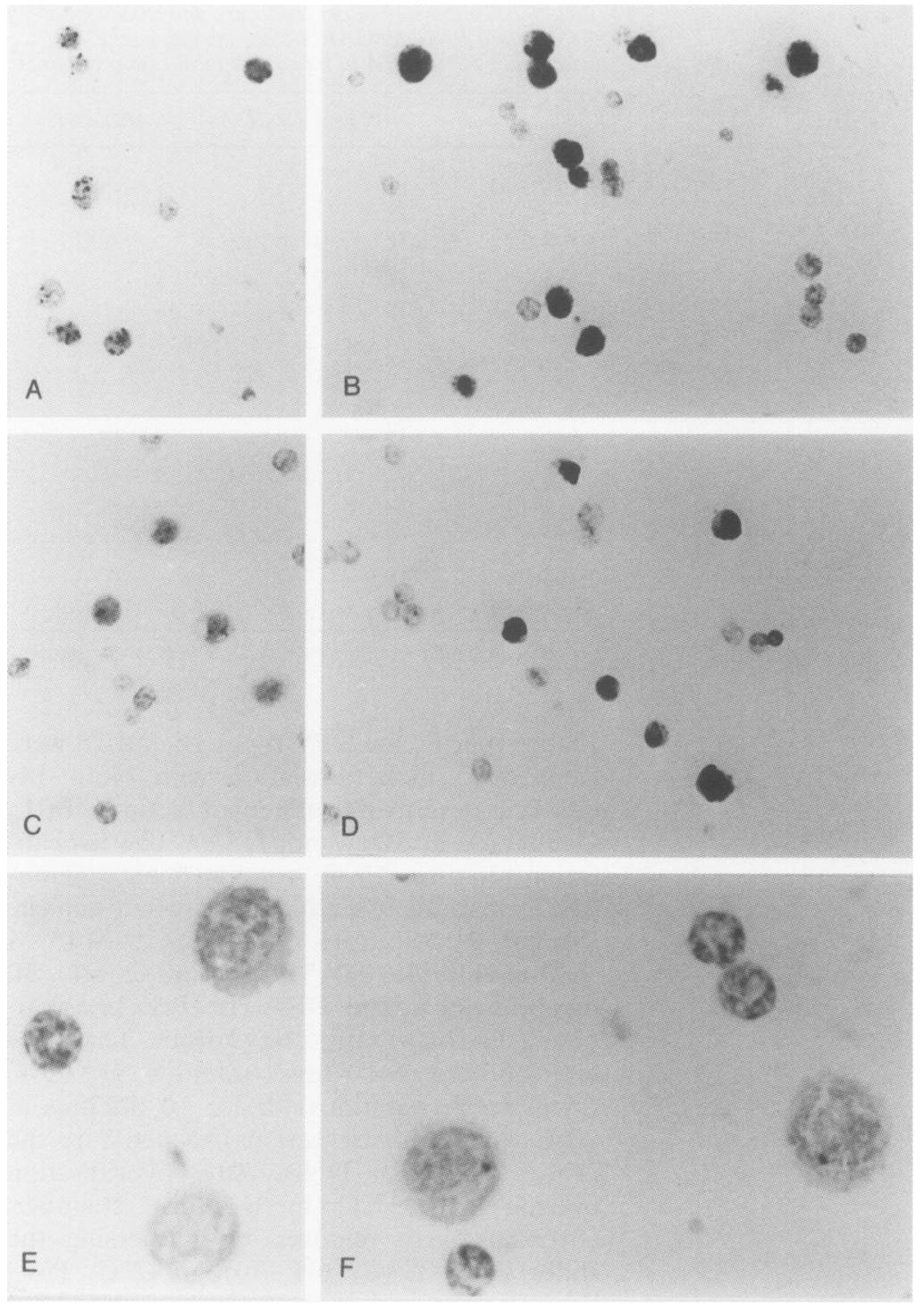

Figure 2 Results of CARD-ISH signal amplification on paraffin wax sections of cell suspensions (see Methods). (A) and (B) CaSki cells hybridised with a DNA probe specific for HPV type 16. (C) and (D) HeLa cells hybridised with a DNA probe specific for HPV type 18. (E) and (F) SiHa cells hybridised with a DNA probe specific for HPV type 16. Visualisation was achieved using the standard $A B C$ technique $(A, C, E)$, and by the $C A R D$ method $(B, D, F)$. Human lymphocytes served as an internal negative control. Original magnification $\times 400(A-D) ; \times 1000(E$ and $F)$.

Table 2 Detection of HPV DNA in cervical lesions of 20 women by ISH and PCR

\begin{tabular}{|c|c|c|c|c|}
\hline \multirow[b]{3}{*}{ Case } & \multirow[b]{3}{*}{ Histology } & \multicolumn{3}{|c|}{ HPV typing } \\
\hline & & \multicolumn{2}{|l|}{$I S H$} & \multirow[b]{2}{*}{$P C R$} \\
\hline & & $A B C$ & $C A R D$ & \\
\hline 1 & Normal & 0 & 0 & 0 \\
\hline 2 & Normal & 0 & 0 & 0 \\
\hline 3 & Normal & 0 & 0 & 0 \\
\hline 4 & Normal & 0 & 0 & 0 \\
\hline 5 & CIN I & 16 & $16^{\star}$ & $\mathrm{X}$ \\
\hline 6 & CIN II & 16 & $16^{\star}$ & 16 \\
\hline 7 & CIN II & 0 & 0 & 0 \\
\hline 8 & CIN II & 0 & 16 & 0 \\
\hline 9 & CIN II & 16 & $16^{\star}$ & 16 \\
\hline 10 & CIN II & 0 & 0 & $\mathrm{x}$ \\
\hline 11 & CIN III & 0 & 16 & 16 \\
\hline 12 & CIN III & 16 & $16^{\star}$ & 16 \\
\hline 13 & CIN III & 16 & $16^{\star}$ & 16 \\
\hline 14 & CIN III & 16 & $16^{\star}$ & 16 \\
\hline 15 & CIN III & 0 & 0 & 0 \\
\hline 16 & Invasive cancer & 0 & 16 & 16 \\
\hline 17 & Invasive cancer & 16 & $16^{\star}$ & 16 \\
\hline 18 & Invasive cancer & 0 & 0 & 0 \\
\hline 19 & Invasive cancer & 16 & $16^{\star}$ & 16 \\
\hline 20 & Invasive cancer & 0 & 16 & 16 \\
\hline
\end{tabular}

$0=$ No HPV DNA detected; $\mathrm{X}=$ unidentified HPV type; *signal amplification.
CONTROLS

The specificity of the ISH reactions was defined by performing CARD-ISH with an HPV type 18 DNA probe on cells containing HPV type 16 (CaSki and SiHa cells) and ISH with the HPV type 16 probe on HeLa cells, which contain copies of HPV type 18 . None of the controls gave specific ISH signals. The addition of human lymphocytes to the cell suspensions served as an internal negative control for all HPV DNA probes.

EVALUATION OF ISH SIGNALS

ISH signals were evaluated using a Leitz DMRB/E microscope and Wild 48/52 photographic equipment (Leica, Wetzlar, Germany).

\section{Results}

DETECTION OF HPV DNA IN CELL SUSPENSIONS Table 1 summarises the results of standard ISH and CARD-ISH on CaSki, HeLa and $\mathrm{SiHa}$ cells. Figure 1 shows the results of routinely applied ISH compared with the CARD-ISH signal amplification method for the detection of HPV DNA in suspensions of HPV containing cell lines mixed with human lymphocytes. Figure 1A shows HPV type 16 in CaSki cells, detected using the conventional $\mathrm{ABC}$ method. Figure $1 \mathrm{~B}$ shows the results of the CARD-ISH signal amplification method. Weak hybridisation signals were observed using the conventional ABC method for the detection of HPV type 18 DNA in HeLa cells (fig 1C). In comparison, application of the CARD-ISH signal amplification method gives very strong hybridisation signals (fig $1 \mathrm{D}$ ). In fig $1 \mathrm{~F}$ one to three copies of HPV type 16 DNA in SiHa cells were visualised using the CARD-ISH method, which is not possible using the conventional $\mathrm{ABC}$ procedure (fig $1 \mathrm{E}$ ).

DETECTION OF HPV DNA IN PARAFFIN WAX SECTIONS

Cell suspensions fixed in formalin and embedded in paraffin wax

HPV DNA was detected in CaSki cells (figs 2A and $2 \mathrm{~B}$ ), $\mathrm{HeLa}$ cells (figs $2 \mathrm{C}$ and $2 \mathrm{D}$ ) and $\mathrm{SiHa}$ cells (figs $2 \mathrm{E}$ and $2 \mathrm{~F}$ ) using the conventional ISH and CARD-ISH signal amplification methods, respectively. As can be seen in figs $2 \mathrm{~B}, 2 \mathrm{D}$, and $2 \mathrm{~F}$, the hybridisation signals generated after CARD-ISH are more intense compared with those generated using the conventional ISH method. Moreover, in fig $2 \mathrm{E}$ no hybridisation signals are visible in $\mathrm{SiHa}$ cells, whereas in fig $2 \mathrm{~F}$ one to three signals can be seen.

Paraffin wax sections of cervical biopsy specimens Table 2 summarises the results of CARD-ISH. The results were compared with the standard ISH ABC method and HPV PCR analysis of the same samples. Figures $3 A$ and $3 B$ show ISH results of case 11 hybridised with the HPV type 16 DNA probe. The sample was HPV negative on conventional ISH (fig $3 \mathrm{~A}$ ) but after CARD-ISH the sample is clearly HPV positive (fig 3B). A representative case (case 14) is shown in figs $3 \mathrm{C}$ and $3 \mathrm{D}$. HPV DNA was not 


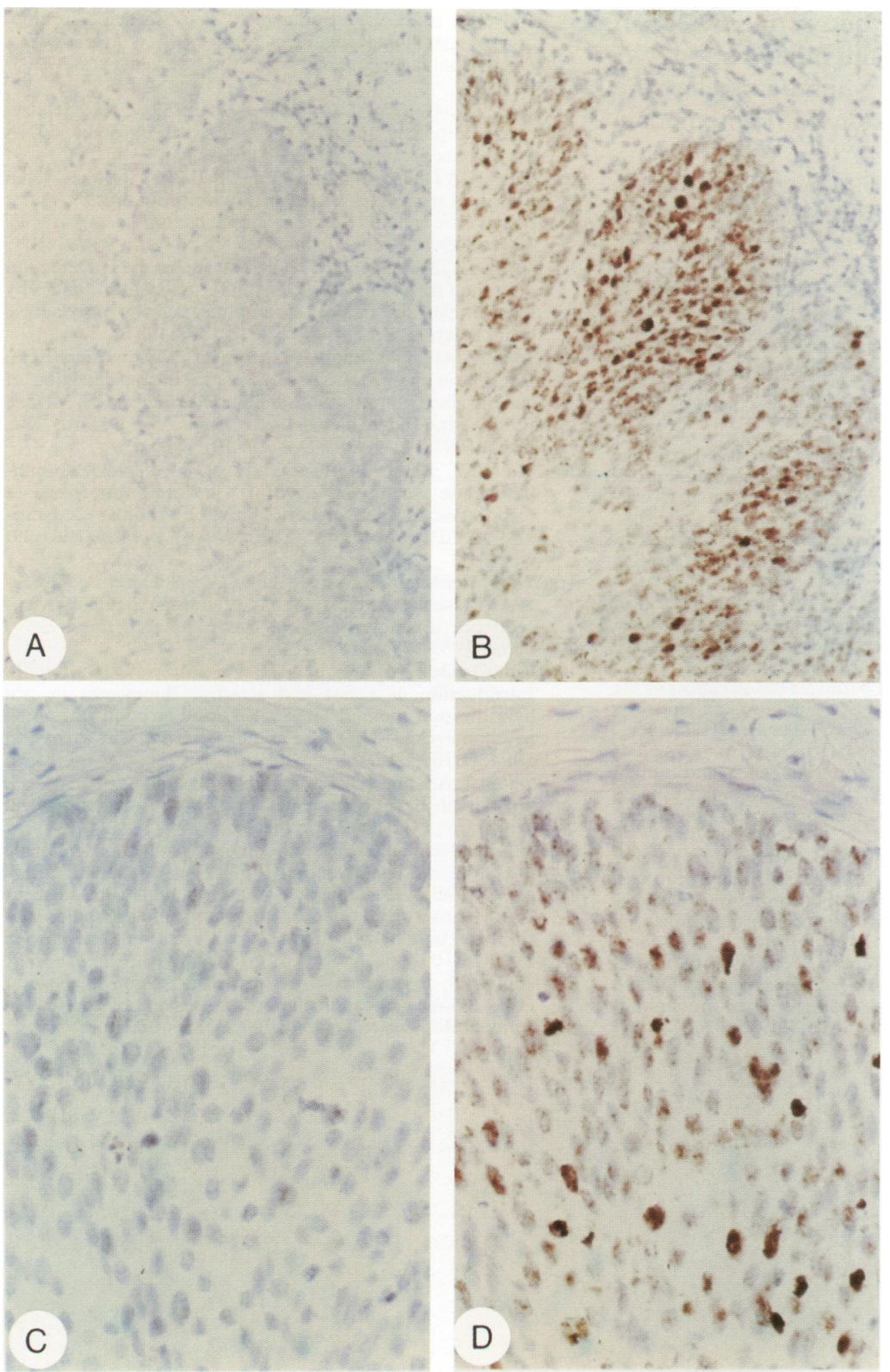

Figure 3 Results of CARD-ISH signal amplification on tissue sections from cases 11 (A and $B$ ) and 14 (C and D), both classified histologically as CIN III. ISH was done with a biotinylated DNA probe specific for HPV type 16 sequences. Visualisation was achieved using the standard $A B C$ technique ( $A$ and $C$ ) and the CARD-ISH signal amplification method $(B$ and $D)$. Original magnification $\times 250$ ( $A$ and $B) ; \times 400(C$ and $D)$.

detected on conventional ISH (fig 3C); on CARD-ISH, however, HPV DNA is clearly visible in the nuclei (fig 3D). No ISH signals were detected on hybridisation of parallel tissue sections with the HPV type 18 DNA probe and the unlabelled HPV type 16 DNA probe (results not shown).

\section{Discussion}

Recently, we described a fast and highly sensitive ISH method (CARD-ISH) for the routine detection of low copy number genome sequences in morphologically intact cells. ${ }^{15}$ In the present study we have compared the sensitivity of this CARD-ISH method with a standard ISH method for the in situ detection of integrated HPV DNA sequences. The latter was carried out using the most sensitive conventional immunochemical detection method-that is, the ABC method. CaSki, $\mathrm{HeLa}$, and $\mathrm{SiHa}$ cell lines were used as model systems because the relative amount of HPV 16
(CaSki: >500 copies/cell; SiHa: one to three copies/cell) and HPV 18 (HeLa: 20-50 copies/ cell) per cell is known. ${ }^{16}$ We found that the CARD-ISH method is more sensitive than conventional ISH and is capable of detecting HPV 16 in SiHa cells (figs $1 \mathrm{~F}$ and $2 \mathrm{~F}$ ) using full length DNA probes, which is in sharp contrast to ISH alone. ${ }^{17}$ By using CARD-ISH signal amplification, minor binding sites may become apparent in some control cells. This non-specific binding can be avoided by adjusting the recommended dilution of the mouse anti-biotin antibody ( 1 in $10^{4}$ instead of 1 in $10^{2}$ ). Conditions for the CARD-ISH signal amplification protocol can also be optimised by adjusting the biotinylated tyramine concentration or the incubation time, or both, in combination with an appropriate $M \alpha B$ dilution. ${ }^{1}$ To detect HPV DNA using CARD-ISH, the highest degree of signal amplification with the highest signal to noise ratio can be obtained for tissue sections by incubating them with a 1 in $10^{3}$ dilution of $M \alpha B$ and $0.07 \mu \mathrm{M}$ biotinylated tyramine for five minutes (fig 3 ).

Cervical carcinoma is one of the most common cancer types in the developed world. As the prognosis of cervical cancer is good if caught and treated early, and given the causal association between infection with high risk HPV types and cervical carcinoma, ${ }^{6-9}$ it is vital that women infected with these high risk HPV types are identified. Recently, it has been shown that worldwide at least $93 \%$ of cervical carcinomas are HPV DNA positive. ${ }^{18}$ In addition to HPV types 16 and 18,13 other oncogenic HPV types have been identified. ${ }^{19}$ In the present study we used probes for HPV types 16 and 18 for ISH and a general HPV probe (primer X) for PCR. This may explain the discrepancies between our ISH and PCR results for cases 5 and 10, but not for case 8 (table 2). At present, the most sensitive method available for the detection of HPV in clinical samples is general primer mediated $\mathrm{PCR}^{19}$ or PCR-ISH. ${ }^{10}$ With our fast and highly sensitive CARD-ISH method it is possible to detect HPV DNA types 16/18 sequences in morphologically preserved samples without the need for PCR amplification (table 2, fig 3). Work to develop a procedure that combines the CARDISH method with a general oncogenic HPV DNA probe that specifically recognises all 15 oncogenic HPV types is underway.

The distribution pattern of HPV DNA is related to the degree of cellular differentiation and viral DNA is most abundant in the more superficial cells. ${ }^{20}$ Whether the virus is also present in the less differentiated basal cells is unknown, as routine ISH is limited by its in situ detection threshold of about 20 copies per cell. ${ }^{18}$ Therefore, we have investigated the cellular localisation of HPV DNA in paraffin wax sections of a large series of cervical lesions using the CARD-ISH method (manuscript in preparation).

In conclusion, CARD-ISH is a fast and highly sensitive ISH method for the routine detection of low copy number HPV DNA sequences in cervical cell lines and routinely processed tissue sections. Application of this 
technology also enables the routine detection and cellular localisation of other viral DNA sequences present at copy numbers below the detection limit of conventional ISH methods We thank Ine Cornelissen for culturing the cell lines and Diana
Willemsen for the PCR analyses. Supported by the Netherlands Willemsen for the PCR analyses. Supp

1 Kerstens HMJ, Poddighe PJ, Hanselaar AGJM. A novel in situ hybridization signal amplification method based on the deposition of biotinylated tyramine. $\mathcal{F}$ Histochem Cytochem 1995; 43:347-52.

2 Bobrow MN, Harris TD, Shaughnessy KJ, Litt GJ Catalyzed reporter deposition, a novel method of signal amplification. I. Application to immunoassays. F Immuno Methods 1989;125:279-85.

3 Bobrow MN, Shaughnessy KJ, Litt GJ. Catalyzed reporter deposition, a novel method of signal amplification. II. Application to membrane immunoassays. $f$ Immunol Meth ods 1991;137:103-12.

4 Adams JC. Biotin amplification of biotin and horseradish peroxidase signals in histochemical stains. $\mathcal{f}$ Histochem peroxidase signals in histoch
Cytochem 1992;40:1457-63.

5 Raap AK, Van de Corput MPC, Vervenne RAW, Van Gijlswijk RPM, Tanke HJ, Wiegant J. Ultra-sensitive FISH using peroxidase-mediated deposition of biotin- or fluorochrome tyramides. Hum Mol Genet 1995;4:529-34.

6 Zur Hausen $\mathrm{H}$ (ed). Molecular pathogenesis of cancer of the cervix and its causation by specific human papillomavirus types. In: Human pathogenic papillomaviruses. Heidelberg, New York: Springer Verlag, 1984:131-56.

7 Koss LG. Carcinogenesis in the uterine cervix and human papillomavirus infection. In: Syrjänen K, Gissman L, Koss LG, eds. Papillomavirusses and human diseases. Heidelberg: LG, eds. Papillomavirusses and
Springer Verlag, 1987:235-67.

8 Walboomers JMM Melchers WJG, Mullink H, Meijer CJLM, Struyk A, Quint WGV, et al. Sensitivity of in situ detection with biotinylated probes of human papillomavirus type $16 \mathrm{DNA}$ in frozen tissue sections of squamous cell carcinomas of the cervix. Am $\mathcal{F}$ Pathol 1988;131:587-94.

9 Schiffman MH, Bauer HM, Hoover RN, Glass AG, Cadel DM, Rush BB, et al. Epidemiological evidence that human papillomavirus infection causes most cervical intraepithelial neoplasia. 7 Natl Cancer Inst 1993;85:958-63.
10 Nuovo GJ (ed). Applications of PCR in situ hybridization: human papillomavirus. In: $P C R$ in situ hybridization: protocols and applications. New York: Raven Press, 1994: protocols $307-49$.

11 Saiki RK, Gelfand DH, Stoffel S. Primer-directed enzymatic amplification of DNA with a thermostable DNA polymerase. Science 1988;239:487-91.

12 Nuovo GJ, Gallery F, MacConnell P, Becker J, Bloch W. An improved technique for the in situ detection of DNA after polymerase chain reaction amplification. Am $f$ Pathol 1991 a;139: 1239-44.

13 Nuovo GJ, MacConnell P, Forde A, Delvenne P. Detection of human papillomavirus DNA in formalin-fixed tissues by in situ hybridization after amplification by polymerase chain reaction. Am f Pathol 1991b;139:847-54.

14 Hopman AHN, Poddighe PJ, Moesker O, Ramaekers FCS Interphase cytogenetics: an approach to the detection of genetic aberrations in tumours. In: Herrington CS, McGee JO'D, eds. Diagnostic molecular pathology. Oxford: IRL JO'D, eds. Diagnostic
Press, 1991:141-63.

$15 \mathrm{Hsu}$ SM, Raine L, Fanger H. Use of avidin-biotinperoxidase complex (ABC) in immunoperoxidase techniques: comparison between $\mathrm{ABC}$ and unlabelled antibody (PAP) procedures. I Histochem Cytochem 1981;29: 577-80.

16 Yee C, Krishnan-Hewlett J, Baker CC, Schlegel R, Howley PM. Presence and expression of human papillomavirus sequence in human cervical carcinoma cell lines. $A m \mathcal{F}$ Pathol 1985;119:361-6.

17 Siadat-Pajouh $M$, Ayscue AH, Periasamy A, Herman B. Introduction of a fast and sensitive fluorescent in situ hybridization method for single-copy detection of human papillomavirus (HPV) genome. $\not$ Histochem Cytochem papillomavirus 1 (1994;42:1503-12.

18 Pontén J, Adami HO, Bergström R, Dillner J, Friberg LG Gustafsson L, et al. Strategies for global control of cervical cancer. Int $\mathcal{f}$ Cancer 1995;60:1-26.

19 de Roda Husman AM, Walboomers JMM, Van den Brule AJC, Meijer CJLM, Snijders PJF. The use of general primers GP5 and GP6 elongated at their 3' ends with adjacent highly conserved sequences improves human papillomavirus detection by polymerase chain reaction. f Gen Virol rus detection by poly

20 Nuovo GJ, Friedman D. In situ hybridization analysis of HPV DNA segregation patterns in lesions of the female genital tract. Gynecol Oncol 1990;36:256-62. 